\title{
Growth and Physiological Factors Involved in Interspecific Variations in Drought Tolerance and Postdrought Recovery in Warm- and Cool-season Turfgrass Species
}

\author{
Jingjin Yu', Mengxian Liu', and Zhimin Yang ${ }^{\mathbf{1}}$ \\ College of Agro-Grassland Science, Nanjing Agricultural University, Nanjing, 210095, P.R. China
}

Bingru Huang

Department of Plant Biology and Pathology, Rutgers University, New Brunswick, NJ 08901

\begin{abstract}
AdDitional INDEX wORDs. water stress, zoysiagrass, kentucky bluegrass, rewatering
Abstract. Drought stress is one of the most important abiotic stresses limiting plant growth, while high recuperative capacity of plants from drought damages is critical for plant survival in periods of drought stress and rewatering. The objective of our study was to determine physiological and growth factors in association with drought tolerance and recuperative capacity of cool-season kentucky bluegrass (Poa pratensis cv. Excursion II) and warm-season zoysigrass (Zoysia matrella cv. Diomand), which were grown in controlled environment chambers and maintained well watered (control) or subjected to drought stress and subsequently rewatering. Compared with kentucky bluegrass, zoysiagrass maintained higher leaf hydration level during drought stress, as shown by greater relative water content (RWC), improved osmotic adjustment (OA), increased leaf thickness, and more extensive root system at deeper soil layers. Turf quality (TQ) and photosynthesis recovered to a greater level and sooner in response to rewatering for zoysiagrass, compared with kentucky bluegrass, which could be due to more rapid reopening of stomata [higher stomatal conductance $\left.\left(g_{\mathrm{S}}\right)\right]$ and leaf rehydration (higher RWC). The aforementioned physiological factors associated with leaf dehydration tolerance during drought and rapid resumption in turf growth and photosynthesis in zoysiagrass could be useful traits for improving drought tolerance in turfgrasses.
\end{abstract}

Drought stress is one of the most important abiotic stresses limiting plant growth in many arid areas. Drought tolerance and recuperative ability differ inter- and intraspecifically for turfgrass species (Carrow, 1996; Du et al., 2008; Pessarakli, 2007; Qian and Fry, 1997). It is generally known that warm-season turfgrass species have better drought tolerance than cool-season species (Fry and Huang, 2004; Pessarakli, 2007; Turgeon, 2011). For example, warm-season species, such as zoysiagrass, seashore paspalum (Paspalum vaginatum), buffalograss (Buchloe dactyloides), and bermudagrass (Cynodon dactylon) were reported to exhibit better TQ and leaf hydration levels or lower level of leaf wilting than cool-season species, such as tall fescue (Festuca arundinacea) during drought stress (Jiang and Carrow, 2005; Qian and Fry, 1997). Various physiological factors could be associated with the interspecific variations in drought tolerance across different turfgrass species (Fry and Huang, 2004; Pessarakli, 2007).

Physiological responses to drought stress vary between warmand cool-season grass species, as reported in different studies. Some cool-season turfgrass species were reported to exhibit earlier leaf rolling and lower level of OA (Qian and Fry, 1997), more rapid decline in membrane stability and photochemical

Received for publication 9 June 2015. Accepted for publication 14 June 2015. We thank the China National Science Foundation (31301799), China Postdoctoral Science Foundation (2013M541688), and Youth Technology Innovation Project from Nanjing Agricultural University (KJ2013021) for providing support.

${ }^{1}$ Authors with equal contribution.

${ }^{2}$ Corresponding author. E-mail: nauyzm@njau.edu.cn. efficiency (Du et al., 2008), and higher water demand or lower water use efficiency (Fu et al., 2007) during drought stress, compared with warm-season species. Despite the general recognition of superior drought tolerance for warm-season turfgrass species relative to cool-season species as a group collectively (Fry and Huang, 2004; Pessarakli, 2007; Turgeon, 2011), the interspecific species variations between individual species within each group, and associated traits accounting for differential drought tolerance are not well documented. In addition, rapid rehydration and regrowth of shoots and roots on water available is critically important for perennial plant species that are often exposed to cyclic periods of drought and rewatering. But few studies examined physiological and morphological traits associated with differential postdrought recuperative ability between warm- and cool-season turfgrass species. Studies with different cultivars within a plant species found that resumption of leaf hydration level, cell membrane stability, and photosynthesis, as well as root production play important roles for plants to recover from drought damages, such as in kentucky bluegrass (Chai et al., 2010; Hu et al., 2010a; Wang and Huang, 2004). Selecting for traits that enable plants to rapidly resume growth and physiological activities from drought stress on rewatering is important for water conservation and can be economical in areas with limited water resources (Norris and Thomas, 1982).

Therefore, the objective of our study was to examine growth and physiological factors in association with drought tolerance and recuperative capacity of a warm-season zoysiagrass and a cool-season kentucky bluegrass. Growth and physiological traits examined in this study during drought stress and rewatering for both turfgrass species including TQ, leaf RWC, OA, leaf 
membrane stability, photosynthetic rate, rate of water loss, specific leaf area (SLA), and leaf wax content (LWC), as well as root length.

\section{Materials and Methods}

Plant material and growth conditions. Sods of zoysiagrass (cv. Diomand) and kentucky bluegrass (cv. Excursion II) were obtained from the research farm at Nanjing Agricultural University in Jiangsu province, China, and transplanted into plastic tubes $(10 \mathrm{~cm}$ diameter, $60 \mathrm{~cm}$ deep) filled with a mixture of fine sand and soil $(1: 1, \mathrm{v} / \mathrm{v})$. Plants were maintained in a greenhouse for 2 months with an average temperature of $30 / 26^{\circ} \mathrm{C}$ (day/night) and natural sun light to establish the canopy and roots. During the period of establishment, plants in each pot in the greenhouse were irrigated twice a week until water draining from the bottom of the pot to maintain soil water content (SWC) at the field capacity level, and fertilized once a week with $400 \mathrm{~mL}$ of half-strength Hoagland's nutrient solution (Hoagland and Arnon, 1950). Grass was maintained at $\approx 10 \mathrm{~cm}$ height by trimming weekly. After establishment, plants were moved to growth chambers (XBQH-1; Jinan Xubang, Jinan, China) set at $70 \%$ relative humidity, $650 \mu \mathrm{mol} \cdot \mathrm{m}^{-2} \cdot \mathrm{s}^{-1}$ photosynthetically active radiation and a 12-h photoperiod. The temperature for zoysiagrass and kentucky bluegrass in growth chamber was $30 / 25^{\circ} \mathrm{C}$ and $25 / 20{ }^{\circ} \mathrm{C}$ (day/night), respectively.

Treatment AND EXPerimental Design. After 2 weeks of acclimation to growth chamber conditions, three treatments were conducted in plants: 1) for well-watered control, plants were watered every other day until drops of water started to drain from the bottom of the pots $(22 \% \mathrm{SWC}), 2)$ for drought treatment, irrigation was withheld until permanent leaf wilting occurred, and 3) for rewatering, plants initially exposed to drought stress by withholding irrigation were irrigated every other day to allow for recovery from drought stress.

Treatments and species were arranged as a split-plot design with species as main plots and water treatments as subplots. Each water treatment was replicated four times in four pots randomly placed in four growth chambers for each grass species (four chambers set at temperature of $30 / 25{ }^{\circ} \mathrm{C}$ for zoysiagrass and for kentucky bluegrass due to warm- and coolseason turfgrass species with different optimal temperature requirement).

Measurements OF SOIL, PLANT GROWTH, AND PHYSIOLOGICAL INDICES. SWC in a $0-20 \mathrm{~cm}$ deep soil layer of each pot was measured as an indication of the level of soil water deficit using time domain reflectometry (Mini Trase Kit 6050X3; Soil Moisture Equipment Corp., Santa Barbara, CA) by inserting the $20-\mathrm{cm}$-long wave guide vertically in the top 20 -cm soil profile.

Turf quality is a widely used parameter evaluating overall plant performance (Turgeon, 2011). Turf quality was visually rated based on turfgrass texture, density, uniformity, and color on a scale from 1 (completely dead plants) to 9 (green and dense canopy).

Leaf RWC of fully expanded leaves were determined by leaf water status based on fresh (FW), turgid (TW), and dry weight (DW) using the following formula: RWC $(\%)=[(\mathrm{FW}-$ $\mathrm{DW}) /(\mathrm{TW}-\mathrm{DW})] \times 100$. Fully expanded leaves were immediately weighed for FW after being excised from the plants, and then placed into tubes filled with deionized water for $12 \mathrm{~h}$ in dark at $4{ }^{\circ} \mathrm{C}$. Leaf samples were then blotted dry and immediately weighed for TW. Samples were then dried in an oven at $80{ }^{\circ} \mathrm{C}$ for at least $72 \mathrm{~h}$ to get DW (Barrs and Weatherley, 1962).

Leaf membrane stability was evaluated by measuring electrolyte leakage (EL) of leaves (Blum and Ebercon, 1981). Fresh fully expanded leaves $(0.1-0.2 \mathrm{~g})$ were collected, rinsed, and immersed in $30 \mathrm{~mL}$ deionized water and placed on a shaker for $24 \mathrm{~h}$. The initial conductivity of the solution $\left(C_{\text {initial }}\right)$ was then measured using a conductivity meter (Orion Star A212; Thermo Scientific, Waltham, MA). Leaves were then killed by autoclaving at $120^{\circ} \mathrm{C}$ for $20 \mathrm{~min}$ and placed back on the shaker for $12 \mathrm{~h}$. The final conductivity of killed tissues $\left(C_{\max }\right)$ was then measured and EL calculated as $\left(C_{\text {initial }} / C_{\text {max }}\right) \times 100$.

To determine differences in rate of water loss and leaf water status during the course of dehydration between the two grass species, relative water leakage (RWL) and RWC of detached leaves were measured (Hu et al., 2010b). Fresh fully expanded leaves were detached and weighed immediately for initial FW, and then placed in petri dishes in a growth chamber with controlled temperature $\left(25^{\circ} \mathrm{C}\right)$, light intensity $\left(150 \mu \mathrm{mol} \cdot \mathrm{m}^{-2} \cdot \mathrm{s}^{-1}\right)$ and relative humidity $(50 \%)$. RWL was determined as the difference of leaf weight (Wt) at a specific time $(\mathrm{T})$ of dehydration $(20,40,60,90,120,150,180,210,240,300,360$, and $420 \mathrm{~min}$ ) from the initial FW relative to the DW: RWL (milligrams per gram DW per minute $)=\{[(\mathrm{FW}-\mathrm{Wt}) / \mathrm{DW} / T]\}$. During rehydration, detached leaves after 240 min dehydration were immersed in water in petri dishes and measured for RWC at 20, $40,60,90,120,150,180$, and 210 min of rewatering to determine water hydration status of detached leaves at a given time of the dehydration process.

Osmotic adjustment was determined by $\Psi_{\mathrm{S}}$ of leaf sap at full turgor. Leaf samples were collected and soaked in deionized water for $4 \mathrm{~h}$, blotted dry, placed into microcentrifuge tubes, frozen in liquid nitrogen, and stored at $-20{ }^{\circ} \mathrm{C}$ until further analysis. Leaf sap was pressed out and added to the chamber in an osmometer (Vapro 5600; Wescor, Logan, UT) for the determination of the osmolality $(C$, value in millimoles per kilogram). Osmolarity of leaf sap was converted from millimoles per kilogram to megapascals using the formula: megapascals $=-C \times 2.58 \times 10^{-3}$. Then, OA was calculated as the difference between the $\Psi_{\mathrm{S}}$ of well-watered control leaves at full turgor and drought-treated leaves at full turgor (Qian and Fry, 1997).

Leaf net photosynthetic rate $\left(P_{\mathrm{n}}\right)$, transpiration rate $\left(T_{\mathrm{r}}\right)$, and $g_{\mathrm{S}}$ were measured at $0,5,10,15$, and $20 \mathrm{~d}$ under drought stress and 2 and $6 \mathrm{~d}$ of rewatering on leaves (second fully expanded from the top) from each pot ( $\mathrm{Yu}$ et al., 2015). Intact leaves were enclosed in a $6-\mathrm{cm}^{2}$ cuvette with a portable infrared gas analyzer (LI-6400; LI-COR, Lincoln, NE). Leaves were placed in a leaf chamber with a built-in red and blue light source of the LI-6400 with the light intensity of $600 \mu \mathrm{mol} \cdot \mathrm{m}^{-2} \cdot \mathrm{s}^{-1}$. The area of leaves enclosed in the leaf chamber was determined on a scanner, which was used to calculate $P_{\mathrm{n}}, g_{\mathrm{S}}$, and $T_{\mathrm{r}}$.

LWC was determined by the method of Zhang et al. (2007). In brief, fresh sample pieces were weighed $\left(\mathrm{FW}_{0}\right)$ and immersed in $30 \mathrm{~mL}$ chloroform for $15 \mathrm{~s}$. The extract was evaporated on a boiling water bath and weighed again to get final weight $\left(\mathrm{FW}_{1}\right)$. Then, leaves were dried in an oven at $80^{\circ} \mathrm{C}$ for at least $72 \mathrm{~h}$ and weighed for DW. LWC was calculated as $\left(\mathrm{FW}_{0}-\mathrm{FW}_{1}\right) / \mathrm{DW}$ (milligrams per gram DW). 
The SLA as an indicator of leaf thinness was measured at 0,5 , 10, 15, and $20 \mathrm{~d}$ under drought stress and 2, 4, and $6 \mathrm{~d}$ of rewatering. For SLA, 20 s-fully expanded leaves from each tube were trimmed off and scanned for fresh leaf area using a scanner (Epson version 2.94A; Seiko Epson Corp., Suwa, Japan) with Digimizer software (version 3.6.0.0; MedCalc Software, Mariakerke, Belgium) to analyze digital images. Then, leaves were dried in an oven at $80{ }^{\circ} \mathrm{C}$ for at least $72 \mathrm{~h}$ and weighed for DW. SLA was calculated as leaf area per unit leaf DW.

All plants were sampled at $20 \mathrm{~d}$ of drought stress and $6 \mathrm{~d}$ of rewatering treatment for an analysis of the root length. The $60-\mathrm{cm}$ soil profile in the $60-\mathrm{cm}$ deep tube was divided into two segments (upper 0-20 cm and lower 20-60 cm). Roots from each segment were then washed free of growth medium and stained in $1 \%$ crystal violet solution. Roots were scanned with a scanner (Epson version 2.94A) to generate root images. The images were then analyzed with Digimizer software (version 3.6.0.0) for their total root length.

Statistical Analysis. Data analysis was performed with SPSS (version 13.0 for Windows; IBM Corp., Armonk, NY). Analysis of variance with a fixed model was used to determine effects of treatment and interaction of treatment and species. When a particular $F$ test was significant, the means were separated with least significance difference test at a probability level of 0.05 .

\section{Results and Discussion}

SOIL WATER STATUS DURING DROUGHT AND POSTDROUGHT REWATERING. Soil water content in pots for both turfgrass species was maintained at $\approx 20 \%$ under well-watered conditions, but exhibited rapid decline during drought stress, to $\approx 5 \%$ at $20 \mathrm{~d}$ of drought stress, and increased to prestress level after rewatering (Fig. 1). SWC content did not differ in pots planted with zoysiagrass from those with kentucky bluegrass, indicating that both zoysiagrass and kentucky bluegrass were exposed to the same level of water deficit during drought stress and rewatering.

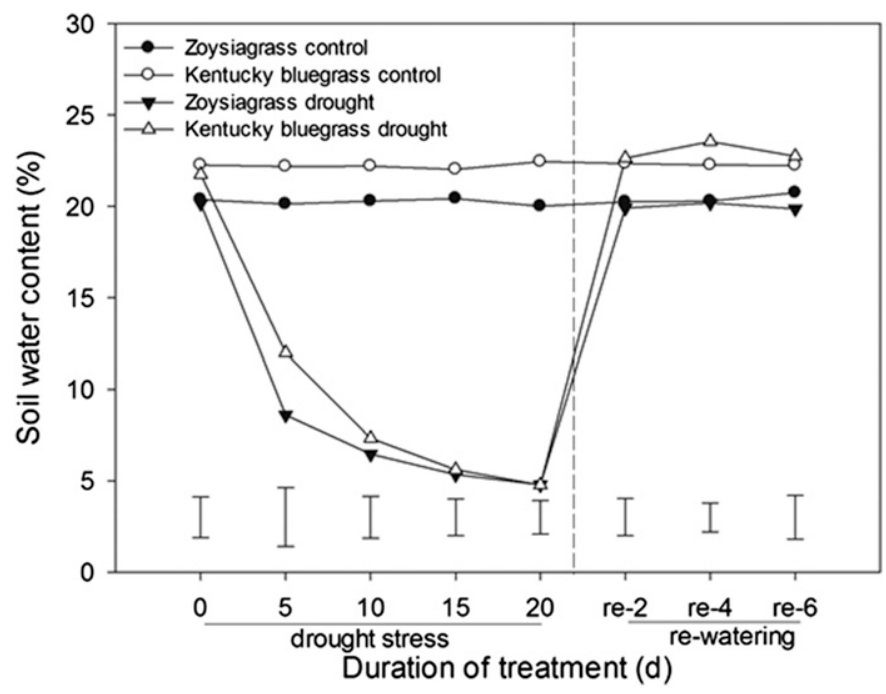

Fig. 1. Changes in soil water content (SWC) in zoysiagrass and kentucky bluegrass exposed to 20 -d drought stress and 6-d rewatering. Vertical bars indicate least significant difference values $(P \leq 0.05)$ for the comparison among treatments at a given sampling day.
INTERSPECIFIC VARIATIONS IN PHYSIOLOGICAL RESPONSES TO DROUGHT AND REWATERING. Turf quality rapidly declined after $15 \mathrm{~d}$ of drought stress in both species, and kentucky bluegrass had a lower TQ of 3.46 than zoysiagrass of 5.0 at $20 \mathrm{~d}$ of treatment (Fig. 2A). Turf quality recovered to prestress level in zoysiagrass, but not in kentucky bluegrass on rewatering for $6 \mathrm{~d}$. These results suggested that zoysiagrass had better drought tolerance and recuperative potential from drought injury compared with kentucky bluegrass. The difference in turf performance in response to drought stress and postdrought rewatering might be associated with physiological changes discussed in this study.

Leaf cell membrane stability has been extensively used as an indicator of cellular damages induced by various stresses, including drought (Blum and Ebercon, 1981). Kentucky bluegrass exhibited rapid increase in EL during $20 \mathrm{~d}$ of drought stress whereas no significant increase in EL was observed in zoysiagrass during the experimental period (Fig. 2B). These results suggested that leaves of zoysiagrass maintained greater membrane stability during drought stress than those of kentucky bluegrass. Du et al. (2008) compared zoysiagrass to another cool-season grass species, tall fescue, and reported that zoysiagrass leaves had a lower droughtinduced EL and higher TQ during drought stress. On rewatering, EL declined rapidly to the level of well-watered control in kentucky bluegrass, which was not significantly different from that of zoysiagrass. The differential EL responses to drought between the two species and the lack of significant differences in EL on rewatering suggested that loss of cellular membrane stability was associated with the greater extent of TQ decline for kentucky bluegrass under drought stress, while other physiological factors rather than EL could play more critical roles in regulating the differential TQ responses to rewatering.

Drought tolerance is closely related to photosynthesis and water loss through transpiration. In this study, $P_{\mathrm{n}}, g_{\mathrm{S}}$, and $T_{\mathrm{r}}$ declined rapidly during drought stress in both species. No significant difference was found in $P_{\mathrm{n}}$ between two species during drought stress, but on postdrought rewatering, leaf $P_{\mathrm{n}}$ was significantly higher in zoysiagrass than that in kentucky bluegrass, which was $68.9 \%$ and $39.4 \%$ of respective well-watered control at $2 \mathrm{~d}$ of rewatering and increased to $93.9 \%$ and $51.5 \%$ of respective well-watered control after $6 \mathrm{~d}$ of rewatering (Fig. 3A). These results suggested that leaves of both species suffered the same level of photosynthetic damages during drought stress, but zoysiagrass leaves had greater recovery potential for rapid resumption of photosynthesis on rewatering. Zoysiagrass leaves exhibited significantly higher $g_{\mathrm{S}}$ and $T_{\mathrm{r}}$ at 10 and $15 \mathrm{~d}$ of drought stress than kentucky bluegrass, which could lead to more water loss, but reflect less damages of stomata by drought stress. On rewatering, stomata of zoysiagrass resumed $g_{\mathrm{S}}$ rapidly, which could contribute to the recovery in photosynthetic activities under rewatering compared with that in kentucky bluegrass. The lesser cellular damages in zoysiagrass leaves during drought stress reflected by lower EL and higher $g_{S}$ was associated with the maintenance of higher leaf hydration status, as manifested by higher RWC in zoysiagrass than kentucky bluegrass during drought stress.

Whole-plant leaf RWC is an extensively used parameter to indicate leaf water status and the level of drought tolerance (Flexas and Medrano, 2002). In this study, no significant difference was observed in RWC between two turfgrass species 

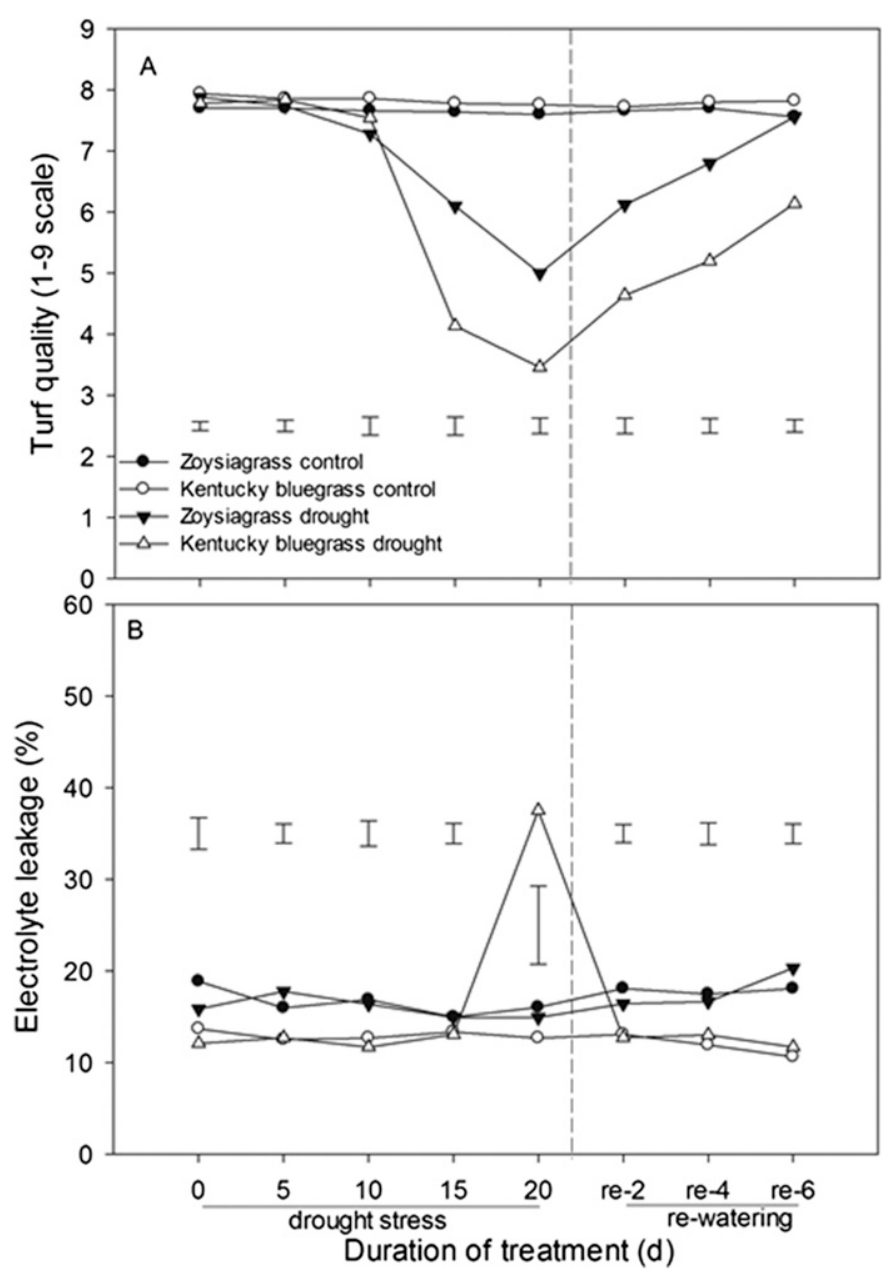

Fig. 2. (A) Changes in turf quality (TQ) and (B) electrolyte leakage (EL) in zoysiagrass and kentucky bluegrass exposed to 20-d drought stress and 6 -d rewatering. TQ was rated based on the scale of $1-9$, with 9 being the best. Vertical bars indicate least significant difference values $(P \leq 0.05)$ for the comparison among treatments at a given sampling day.

under well-watered conditions (Fig. 4). Drought caused rapid decrease in RWC after $10 \mathrm{~d}$ of treatment in both species, and kentucky bluegrass maintained lower water status than zoysiagrass, to $23.4 \%$ and $43.7 \%$ at the end of drought stress, respectively. In perennial kentucky bluegrass, $25 \%$ of leaf RWC was reported to be a critical point for whole plant to survive (Xu et al., 2011a, 2011b, 2013). On rewatering, RWC was sharply increased to $97.1 \%$ in zoysiagrass, reaching the same level of the well-watered control after only $2 \mathrm{~d}$ of water rehydration. However, kentucky bluegrass did not fully recover to the level of control even with $6 \mathrm{~d}$ of rewatering, only to $80.3 \%$ of well-watered control. These results suggested that zoysiagrass developed a stronger adaptation strategy for leaf water maintenance during drought stress and rehydration during postdrought rewatering. Leaf cellular water status during drought stress is in association with OA and morphological indexes, which is discussed below.

Zoysiagrass leaves had lower RWL than kentucky bluegrass, which was $30.8 \%$ lower at the first 20 min of dehydration (Fig. $5 \mathrm{~A})$. The significant difference maintained until $300 \mathrm{~min}$ of dehydration. The above results indicated that zoysiagrass had better water retention ability compared with kentucky bluegrass

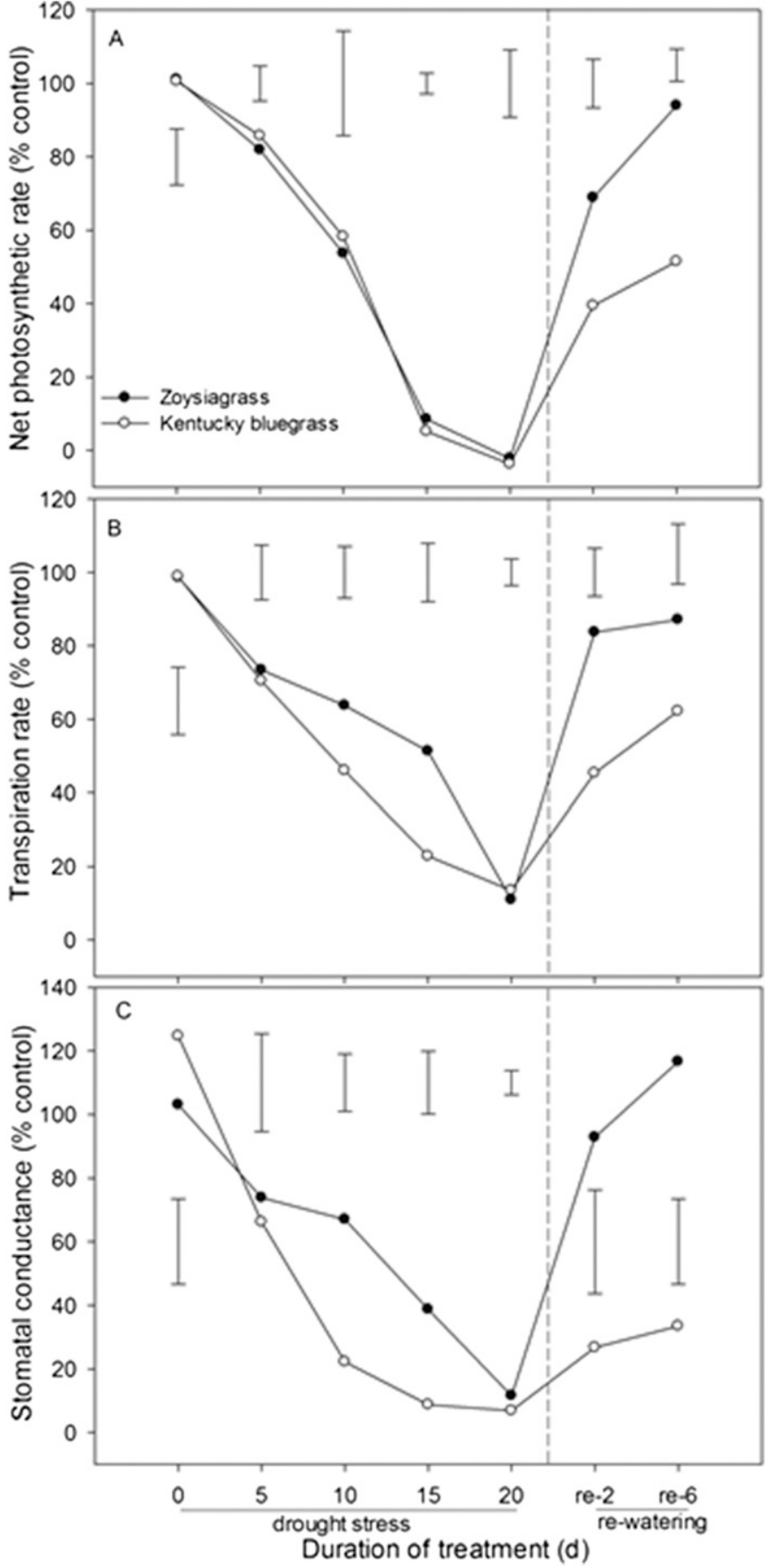

Fig. 3. (A) Changes in net photosynthetic rate $\left(\mathrm{P}_{\mathrm{n}}\right),(\mathbf{B})$ transpiration rate $\left(\mathrm{T}_{\mathrm{r}}\right)$, and $(\mathbf{C})$ stomatal conductance $\left(g_{\mathrm{S}}\right)$ in zoysiagrass and kentucky bluegrass exposed to 20 -d drought stress and 6-d rewatering. Vertical bars indicate least significant difference values $(P \leq 0.05)$ for the comparison among treatments at a given sampling day.

during the beginning and mild water deficit conditions, which was consistent with the result of whole-plant response to drought stress. On rehydration, detached leaves of both turfgrass species absorbed water rapidly, and zoysiagrass showed significantly higher RWC than kentucky bluegrass after 40 min of rewatering, from $43.4 \%$ and $44.4 \%$ to $98.2 \%$ and $91.4 \%$ of well-watered control, respectively (Fig. 5B). Results from 


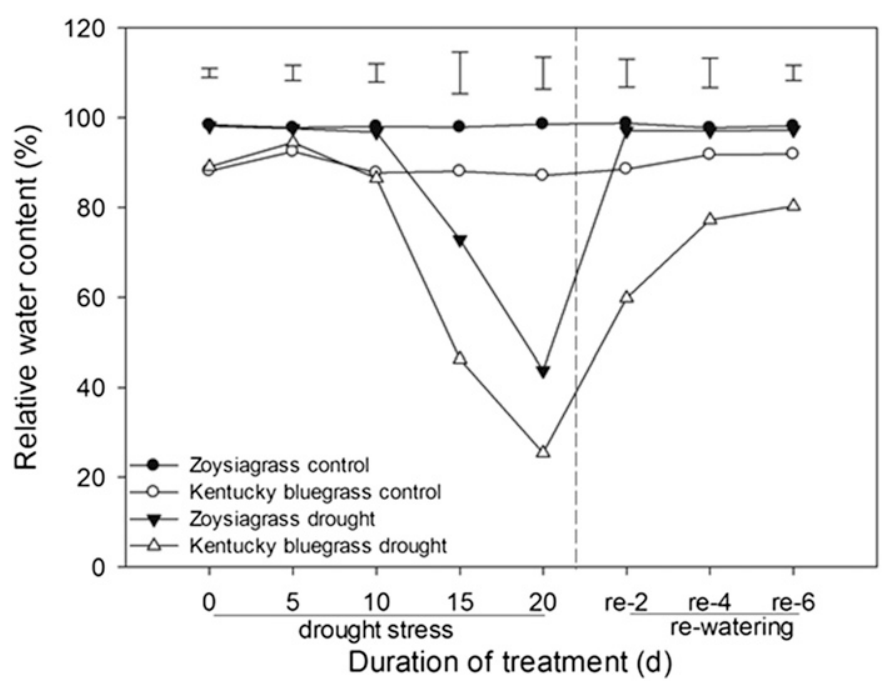

Fig. 4. Changes in leaf relative water content (RWC) in zoysiagrass and kentucky bluegrass exposed to 20-d drought stress and 6-d rewatering. Vertical bars indicate least significant difference (LSD) values $(P \leq 0.05)$ for the comparison among treatments at a given sampling day.
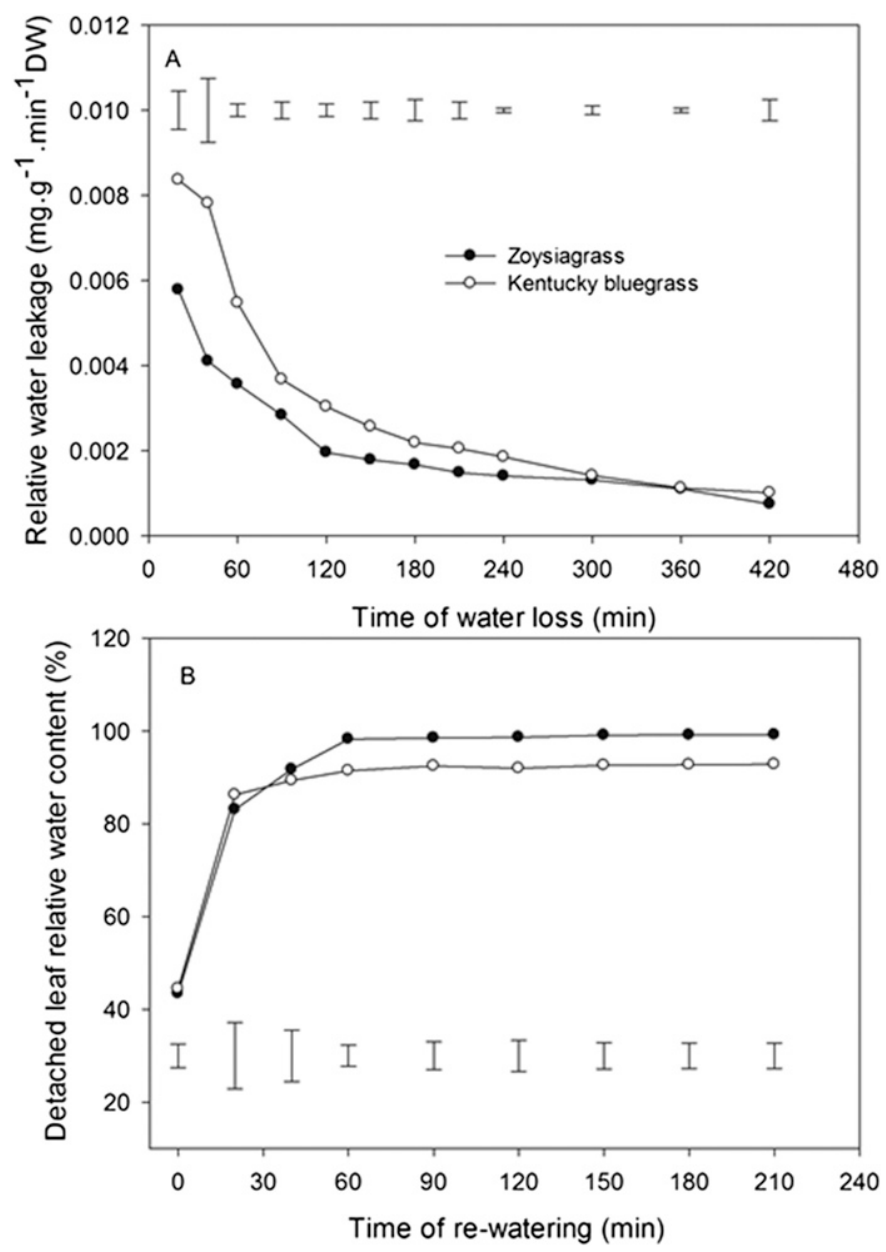

Fig. 5. (A) Changes in detached leaf relative water leakage (RWL) and (B) water content in leaves after 240 min drought in zoysiagrass and kentucky bluegrass exposed to 20-d drought stress and 6-d rewatering. Vertical bars indicate least significant difference values $(P \leq 0.05)$ for the comparison among treatments at a given sampling day. detached leaves that underwent dehydration and rehydration suggested that zoysiagrass could maintain more leaf water through slow water loss and fast water absorption, compared with kentucky bluegrass.

OA plays important roles in cellular water retention and turgor maintenance among many physiological factors when water deficit occurs in plants (Farooq et al., 2009; Huang, 2008; Kramer and Boyer, 1995). In this study, OA of zoysiagrass increased from 0.02 to $0.67 \mathrm{MPa}$ during drought treatment, but from 0.04 to $0.52 \mathrm{MPa}$ for that of kentucky bluegrass (Fig. 6A). A significantly higher $\mathrm{OA}$ in zoysiagrass was found at 15 and $20 \mathrm{~d}$ of drought stress, compared with that in kentucky bluegrass. On $2 \mathrm{~d}$ of rewatering, OA of both turfgrass species declined rapidly and zoysiagrass was observed with significant higher OA during postdrought rewatering, except that at $6 \mathrm{~d}$ of rewatering. These results indicated that zoysiagrass retained greater RWC using OA capacity during drought stressed period and postdrought rewatering, compared with that of kentucky bluegrass. Previous studies also observed warm-season zoysiagrass $(0.77 \mathrm{MPa})$ had higher OA than cool-season tall fescue $(0.34 \mathrm{MPa})$ during drought stress (Qian and Fry, 1997), the same as Barker et al. (1993). The enhanced OA was attributed to the accumulation of some compatible solutes, such as water-soluble sugars, proline and glycine betaine during various abiotic stresses (Geissler et al., 2009; Pérez-López et al., 2010; Wang et al., 2004; Yu et al., 2015). The specific mechanism for the higher OA in zoysiagrass compared with kentucky bluegrass needs to be further measured and confirmed in future studies.

Specific leaf area as an indicator of leaf thickness has often been observed to decline under water deficit conditions and drought tolerant plants exhibit lower SLA than drought sensitive ones (Liu and Stutzel, 2004; Marron et al., 2003). In this study, SLA in zoysiagrass and kentucky bluegrass showed a significant decline with the duration of drought stress, to $37.5 \%$ and $49.1 \%$ of respective well-watered control at $20 \mathrm{~d}$ of drought treatment (Fig. 6B). However, on $6 \mathrm{~d}$ of rewatering, SLA in zoysiagrass rose more rapidly to $94.5 \%$ of well-watered control than that in kentucky bluegrass $(81.3 \%)$. Decline in SLA was an adaptive strategy for plants to limit leaf water loss through reduced leaf area and transpiration rate under drought conditions (Craufurd et al., 1999; Marron et al., 2003). Results from this study indicated that SLA could be involved in leaf water maintenance in zoysiagrass in response to postdrought rewatering.

Leaf wax content is another indicator of drought resistance used in various plant species (Chen et al., 2015; Haque et al., 1992; Seo et al., 2011). Leaf rolling and LWC exhibited a positive effect on leaf water maintenance in weeping lovegrass (Eragrostis curvula) plants (Colom and Vazzana, 2003). Zoysiagrass exhibited significant higher LWC in plants grown under either well-watered control or drought stress conditions compared with kentucky bluegrass (Fig. 6C), indicating that LWC, along with other leaf physiological and morphological traits, played important roles in the maintenance of higher leaf water status in zoysiagrass.

The higher leaf water status during drought stress can be attributable to active growing and extensive root system (Henry et al., 2011). Plants with a deeper root system usually had higher drought avoidance capacity than plants with shallow root systems (Carrow, 1996; Huang and Gao, 1999; Su et al., 2008), but few studies examined root regrowth after rewatering for different plant species. In this study, no significant differ- 

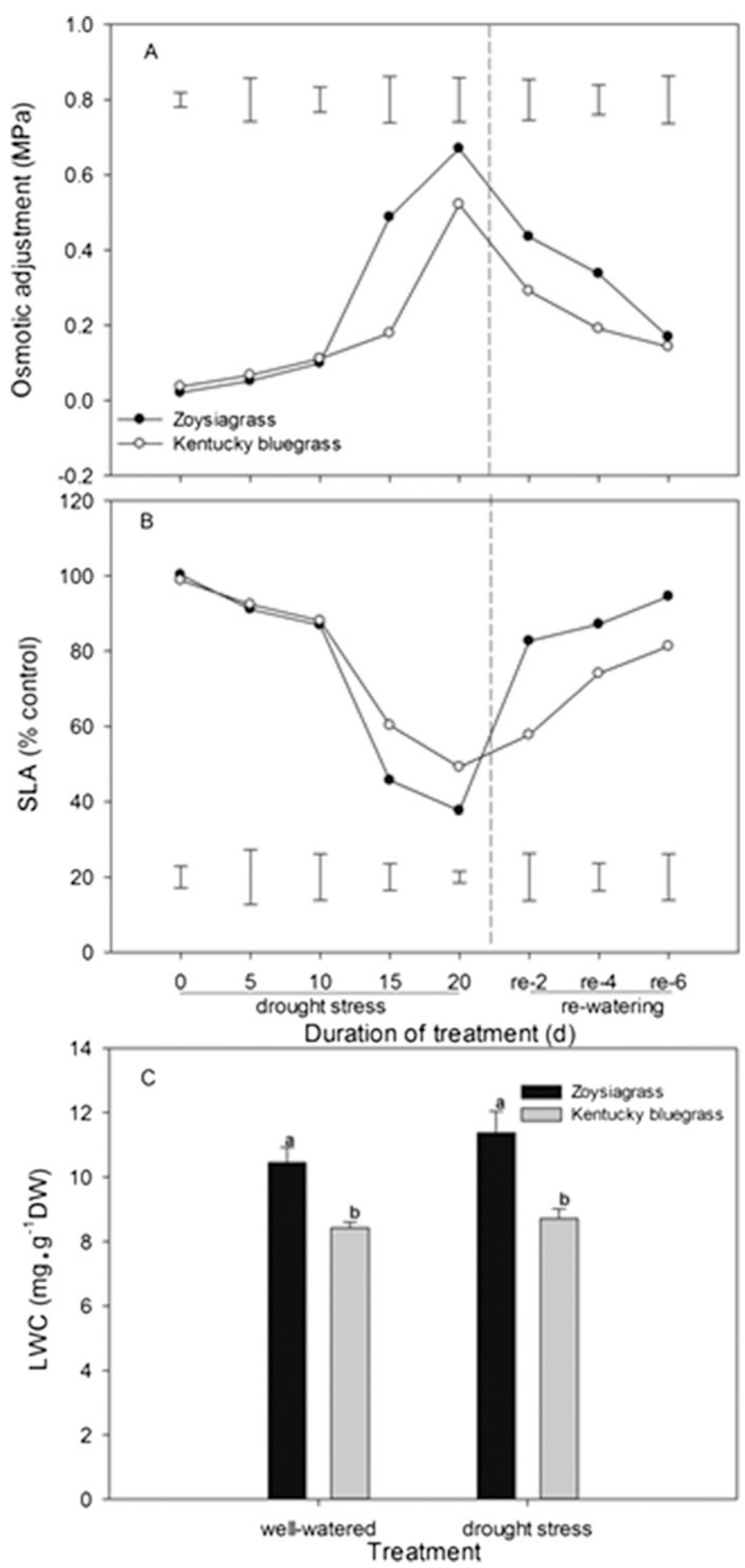

Fig. 6. (A) Changes in leaf osmotic adjustment (OA), (B) specific leaf area (SLA) in zoysiagrass and kentucky bluegrass exposed to 20 -d drought stress and 6-d rewatering, and (C) leaf wax content (LWC) at $6 \mathrm{~d}$ of rewatering. Vertical bars indicate least significant difference values [LSD $(P \leq 0.05)]$ for the comparison among treatments at a given sampling day in $\mathbf{A}$ and $\mathbf{B}$. Different letters indicate significant differences based on LSD test $(P \leq 0.05)$ between the same treatment in $\mathbf{C}$. The vertical bar over each column was SE for four replicates in $\mathbf{C}$.

ence in total root length was found between zoysiagrass and kentucky bluegrass in the upper soil layers of $0-20 \mathrm{~cm}$ at the $20 \mathrm{~d}$ of drought treatment (Fig. 7A). However, zoysiagrass developed more root in the deeper soil layers of 20-50 cm compared with kentucky bluegrass that could transport and

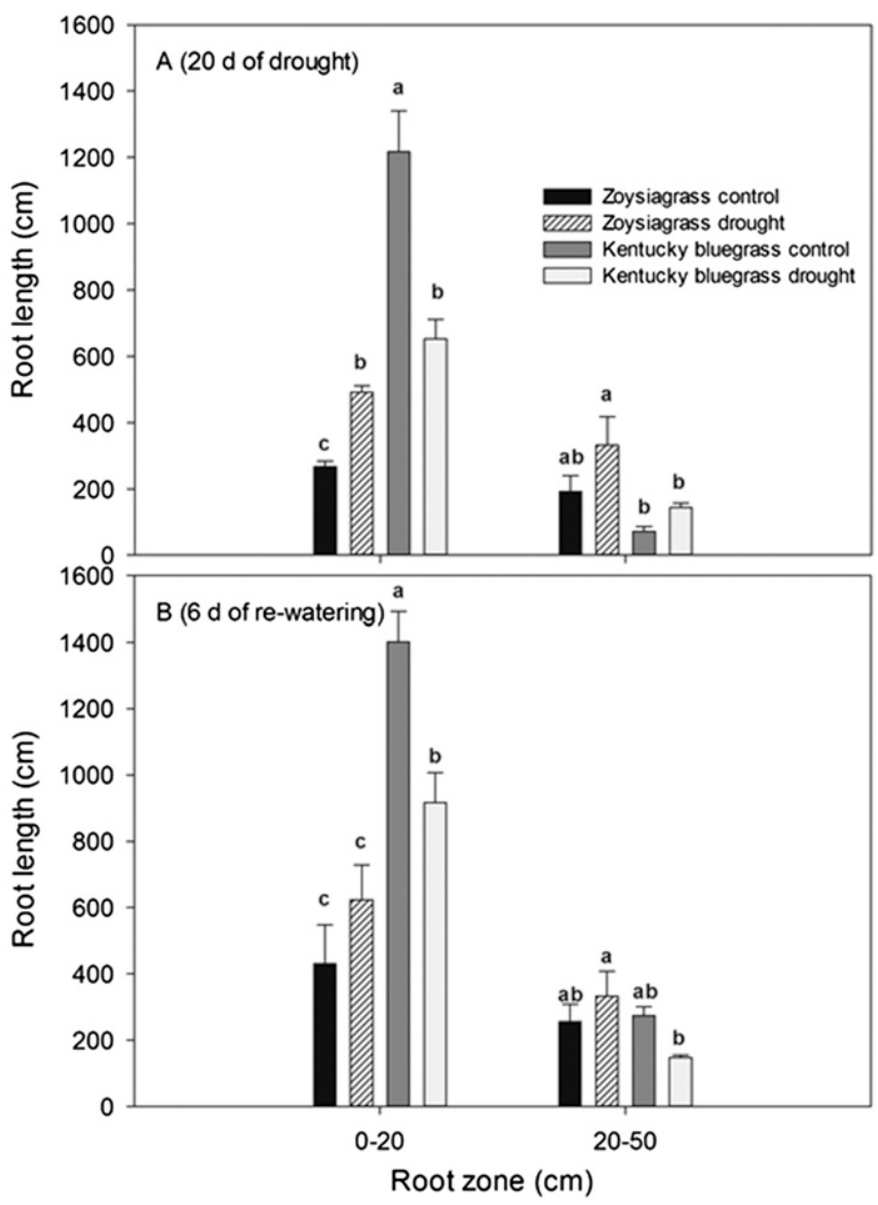

Fig. 7. (A) Changes in root length in zoysiagrass and kentucky bluegrass at 20-d drought stress and (B) 6-d rewatering. Different letters indicate significant differences based on least significant difference test $(P \leq 0.05)$ among the same soil layer. The vertical bar over each column was SE for four replicates.

provide water from deeper soil to aboveground plants. On $6 \mathrm{~d}$ of rewatering, kentucky bluegrass developed more roots in upper soil layers of 0-20 cm, but fewer roots in the deeper soil layers of 20-50 cm (Fig. 7B) compared with zoysiagrass under drought stress. The more extensive roots in the deeper soil profile in zoysiagrass during drought stress and rewatering could facilitate water uptake from deeper soil profile, which is vital for plants to avoid drought stress and the resumption of growth after rewatering.

In summary, warm-season zoysiagrass had superior drought tolerance and postdrought recovery compared with cool-season kentucky bluegrass as shown by better turf performance (TQ) and RWC. Leaves of zoysiagrass maintained higher leaf hydration level during drought stress, as shown by greater RWC, which could be associated with higher leaf cellular membrane stability, improved OA, increased leaf thickness (lower SLA), and more extensive root system at deeper soil profile. The rapid resumption of TQ and photosynthesis could be due to rapid reopening of stomata (higher $g_{\mathrm{S}}$ ) and leaf rehydration (higher RWC). Those abovementioned growth and physiological traits could be used as screening parameter to select for drought-tolerant turfgrass germplasm that can tolerate prolonged periods of drought stress and recuperate from drought stress quickly on rewatering. 


\section{Literature Cited}

Barker, D.J., C.Y. Sullivan, and L.E. Moser. 1993. Water deficit effects on osmotic potential, cell wall elasticity, and proline in five forage grasses. Agron. J. 85:270-275.

Barrs, H.D. and P.E. Weatherley. 1962. A re-examination of the relative turgidity techniques for estimating water deficits in leaves. Austral. J. Biol. Sci. 15:413-428.

Blum, A. and A. Ebercon. 1981. Cell membrane stability as a measure of drought and heat tolerance in wheat. Crop Sci. 21:43-47.

Carrow, R.N. 1996. Drought avoidance characteristics of diverse tall fescue cultivars. Crop Sci. 36:371-377.

Chai, Q., J. Fang, and B. Huang. 2010. Growth and physiological traits associated with drought survival and post-drought recovery in perennial turfgrass species. J. Amer. Soc. Hort. Sci. 135:125-133.

Chen, Y.J., J.J. Yu, and B.R. Huang. 2015. Effects of elevated $\mathrm{CO}_{2}$ concentration on water relations and photosynthetic responses to drought stress and recovery during rewatering in tall fescue. J. Amer. Soc. Hort. Sci. 140:1-8.

Colom, M.R. and C. Vazzana. 2003. Photosynthesis and PSII functionality of drought-resistant and drought-sensitive weeping lovegrass plants. Environ. Expt. Bot. 49:135-144.

Craufurd, P.Q., T.R. Wheeler, R.H. Ellis, R.J. Summerfield, and J.H. Williams. 1999. Effect of temperature and water deficit on water-use efficiency, carbon isotope discrimination, and specific leaf area in peanut. Crop Sci. 39:136-142.

Du, H., Z. Wang, and B. Huang. 2008. Differential responses of tall fescue and zoysiagrass to heat and drought stress. Acta Hort. 783:207-214.

Farooq, M., A. Wahid, N. Kobayashi, D. Fujita, and S.M.A. Basra. 2009. Plant drought stress: Effects, mechanisms and management. Agron. Sustain. Dev. 29:185-212.

Flexas, J. and H. Medrano. 2002. Drought-inhibition of photosynthesis in $\mathrm{C}_{3}$ plants: Stomatal and non-stomatal limitations revisited. Ann. Bot. (Lond.) 89:183-189.

Fry, J. and B. Huang. 2004. Applied turfgrass science and physiology. Wiley, Hoboken, NJ.

Fu, J., J.D. Fry, and B. Huang. 2007. Growth and carbon metabolism of tall fescue and zoysiagrass as affected by deficit irrigation. HortScience 42:378-381.

Geissler, N., S. Hussin, and H. Koyro. 2009. Interactive effects of $\mathrm{NaCl}$ salinity and elevated atmospheric $\mathrm{CO}_{2}$ concentration on growth, photosynthesis, water relations and chemical composition of the potential cash crop halophyte Aster tripolium L. Environ. Expt. Bot. 65:220-231.

Haque, M.M., D.J. Mackill, and K.T. Ingram. 1992. Inheritance of leaf epicuticular wax content in rice. Crop Sci. 32:865-868.

Henry, A., V.R.P. Gowda, R.O. Torres, K.L. McNally, and R. Serraj. 2011. Variation in root system architecture and drought response in rice (Oryza sativa): Phenotyping of the OryzaSNP panel in rainfed lowland fields. Fuel Energy Abstr. 120:205-214.

Hoagland, D.R. and D.I. Arnon. 1950. The water-culture method for growing plans without soil. California Agr. Expt. Sta. Circ. 347.

Hu, L., Z. Wang, and B. Huang. 2010a. Diffusion limitations and metabolic factors associated with inhibition and recovery of photosynthesis from drought stress in $\mathrm{a}_{3}$ perennial grass species. Physiol. Plant. 139:93-106.

Hu, L.X., Z.L. Wang, H.M. Du, and B.R. Huang. 2010b. Differential accumulation of dehydrins in response to water stress for hybrid and common bermudagrass genotypes differing in drought tolerance. J. Plant Physiol. 167:103-109.

Huang, B. 2008. Mechanisms and strategies for improving drought resistance in turfgrass. Acta Hort. 783:221.
Huang, B. and H. Gao. 1999. Physiological responses of diverse tall fescue cultivars to drought stress. HortScience 34:897-901.

Jiang, Y. and R.N. Carrow. 2005. Assessment of narrow-band canopy spectral reflectance and turfgrass performance under drought stress. HortScience 40:242-245.

Kramer, P.J. and J. Boyer. 1995. Water relations of plants and soils. Academic Press, San Diego, CA.

Liu, F. and H. Stutzel. 2004. Biomass partitioning, specific leaf area, and water use efficiency of vegetable amaranth (Amaranthus spp.) in response to drought stress. Sci. Hort. 102:15-27.

Marron, N., E. Dreyer, E. Boudouresque, D. Delay, J. Petit, F.M. Delmotte, and F. Brignolas. 2003. Impact of successive drought and re-watering cycles on growth and specific leaf area of two Populus $\times$ canadensis (Moench) clones, 'Dorskamp' and 'Luisa_Avanzo'. Tree Physiol. 23:1225-1235.

Norris, I.B. and H. Thomas. 1982. The effects of cutting on regrowth of perennial ryegrass selections exposed to drought conditions. J. Agr. Sci. 99:547-553.

Pérez-López, U., A. Robredo, M. Lacuesta, A. Muñoz-Rueda, and A. Mena-Petite. 2010. Atmospheric $\mathrm{CO}_{2}$ concentration influences the contributions of osmolyte accumulation and cell wall elasticity to salt tolerance in barley cultivars. J. Plant Physiol. 167:15-22.

Pessarakli, M. 2007. Handbook of turfgrass management and physiology. CRC Press, Boca Raton, FL.

Qian, Y. and J. Fry. 1997. Water relations and drought tolerance of four turfgrasses. J. Amer. Soc. Hort. Sci. 122:129-133.

Seo, P.J., S.B. Lee, M.C. Suh, M. Park, Y.S. Go, and C. Park. 2011. The MYB96 transcription factor regulates cuticular wax biosynthesis under drought conditions in arabidopsis. Plant Cell 23:1138-1152.

Su, K., D.J. Bremer, S.J. Keeley, and J.D. Fry. 2008. Rooting characteristics and canopy responses to drought of turfgrasses including hybrid bluegrasses. Agron. J. 100:949-956.

Turgeon, A.J. 2011. Turfgrass management. 9th ed. Prentice Hall, Upper Saddle River, NJ.

Wang, Z. and B. Huang. 2004. Physiological recovery of kentucky bluegrass from simultaneous drought and heat stress. Crop Sci. 44:1729-1736.

Wang, Z., B. Huang, S. Bonos, and W. Meyer. 2004. Abscisic acid accumulation in relation to drought tolerance in kentucky bluegrass. HortScience 39:1133-1137.

Xu, L., J. Yu, L. Han, and B. Huang. 2013. Photosynthetic enzyme activities and gene expression associated with drought tolerance and post-drought recovery in kentucky bluegrass. Environ. Expt. Bot. 89:28-35.

Xu, L., L. Han, and B. Huang. 2011a. Antioxidant enzyme activities and gene expression patterns in leaves of kentucky bluegrass in response to drought and post-drought recovery. J. Amer. Soc. Hort. Sci. 136:247-255.

Xu, L., L. Han, and B. Huang. 2011b. Membrane fatty acid composition and saturation levels associated with leaf dehydration tolerance and post-drought rehydration in kentucky bluegrass. Crop Sci. 51:273-281.

Yu, J., L. Sun, N. Fan, Z. Yang, and B. Huang. 2015. Physiological factors involved in positive effects of elevated carbon dioxide concentration on bermudagrass tolerance to salinity stress. Environ. Expt. Bot. 115:20-27.

Zhang, Z., L. Rao, Z. Xiang, X. Hu, and X. Wang. 2007. Epidermis wax content and drought resistance among different tall fescue (Festuca arundinacea Schreb.) varieties [in Chinese with English Abstract]. Acta Bot. Boreali-Occidentalia Sinica 27:1417-1421. 